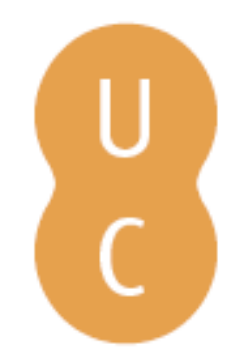

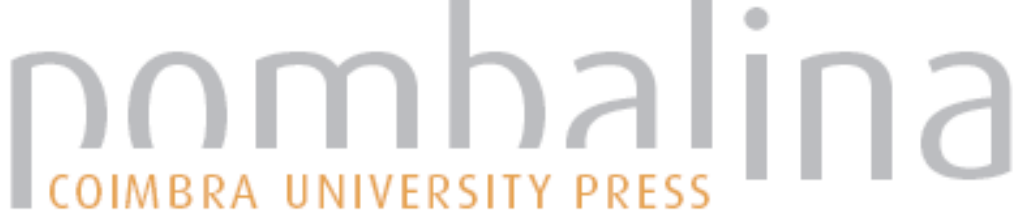

\section{O espaço no conto de Eros e Psique}
Autor(es):
Bárbara, Maria Leonor Santa
Publicado por: $\begin{aligned} & \text { Associação Portuguesa de Estudos Clássicos; Imprensa da } \\ & \text { Universidade de Coimbra }\end{aligned}$

URL

persistente:

URI:http://hdl.handle.net/10316.2/31796

DOI:

DOI:http://dx.doi.org/10.14195/978-989-721-069-3_32

Accessed : $\quad$ 26-Apr-2023 14:11:01

A navegação consulta e descarregamento dos títulos inseridos nas Bibliotecas Digitais UC Digitalis, UC Pombalina e UC Impactum, pressupõem a aceitação plena e sem reservas dos Termos e Condições de Uso destas Bibliotecas Digitais, disponíveis em https://digitalis.uc.pt/pt-pt/termos.

Conforme exposto nos referidos Termos e Condições de Uso, o descarregamento de títulos de acesso restrito requer uma licença válida de autorização devendo o utilizador aceder ao(s) documento(s) a partir de um endereço de IP da instituição detentora da supramencionada licença.

Ao utilizador é apenas permitido o descarregamento para uso pessoal, pelo que o emprego do(s) título(s) descarregado(s) para outro fim, designadamente comercial, carece de autorização do respetivo autor ou editor da obra.

Na medida em que todas as obras da UC Digitalis se encontram protegidas pelo Código do Direito de Autor e Direitos Conexos e demais legislação aplicável, toda a cópia, parcial ou total, deste documento, nos casos em que é legalmente admitida, deverá conter ou fazer-se acompanhar por este aviso.

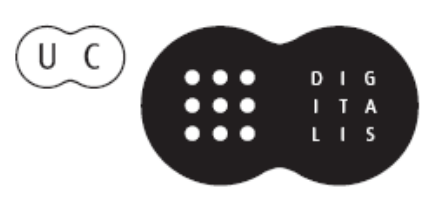




\section{Espaços e Paisagens}

\section{Antiguidade Clássica e Heranças Contemporâneas}

Vol. I Línguas e Literaturas. Grécia e Roma

Francisco de Oliveira, Cláudia Teixeira, Paula Barata Dias (coords.)

IMPRENSA DA UNIVERSIDADE DE COIMBRA 


\title{
O ESPAÇO NO CONTO DE EROS E PSIQUE
}

\author{
Maria Leonor Santa Bárbara \\ Centro de História da Cultura (UNL)
}

\begin{abstract}
When we talk about the question of space in the tale of Cupid and Psyche, we must consider two aspects: first, that there is a clear relation between this story and Apuleius' novel; then, that we find two kinds of space, crossing each other, the human and the one of the gods. Afterwards, there's another element to take into account: the relation between this story and folktales. Psyche's story presents a clear similitude to that of Lucius but, at the same time, it seems a tale for children, as some of its features confirm. This implies that we have to see the question of space according to the marvellous and the inexistence of a specific space in it.
\end{abstract}

Keywords: Apuleius, The Golden Ass, tale of Cupid and Psyche.

Palavras-chave: Apuleio, O Burro de Ouro, conto de Amor e Psique.

Falar de espaço suscita várias questões: que espaço? Geográfico? Idílico? Imaginário? Espaço divino? Espaço humano? Se atentarmos nos poemas homéricos, por exemplo, deparamo-nos com a existência de diversos espaços, já que a acção decorre em dois níveis - humano e divino - e, simultaneamente, num dos poemas temos ainda, a par do espaço real, o imaginário, representando o percurso do herói por um mundo totalmente desconhecido e maravilhoso. Ao longo dos textos que a Antiguidade nos legou continuamos a encontrar várias descrições de espaços, reais ou imaginários, frequentemente associados a paisagens. O romance de Apuleio, O Burro de Ouro, não é excepção. E, porque de uma viagem se trata, as descrições vão-se sucedendo, ainda que nem sempre tenhamos uma localização geográfica dos diversos locais em que decorre a acção. Mas tudo isto se altera quando atentamos numa das narrativas inseridas neste romance, o conto de Amor e Psique.

Ao abordar a questão do espaço neste conto importa considerar, por um lado, a relação existente entre ele e o romance de Apuleio e, por outro, a sua relação com o conto infantil. Ou seja, ver de que modo o conto se insere no romance e é um reflexo seu, bem como o modo como se aproxima, pela estrutura e pelo conteúdo, do conto infantil.

\section{O Burro de Ouro: narrativas e narradores}

O Burro de Ouro não apresenta propriamente uma estrutura simples, muito embora, numa primeira leitura possa parecer um romance bastante 
linear e com um objectivo claro. De facto, existe uma narrativa principal, feita na primeira pessoa pelo herói do romance, Lúcio, que conta todas as peripécias por que passa desde que chega à Tessália e se vê, inesperadamente, transformado em burro, até recuperar a forma humana, tornando-se num fiel servidor de Ísis e de Osíris. Mas, a par dela, surgem-nos outras, de extensão variável, contadas tanto pelo próprio narrador, como por outros narradores. É o caso do episódio de Sócrates, contado por Aristómenes, da história de Télifron contada pelo próprio, ou do conto de Amor e Psique, uma história contada por uma velha a Cárite, a jovem noiva roubada ${ }^{1}$. Outras narrativas poderiam ser referidas, como as histórias dos próprios ladrões, ou até uma enumeração de todas as histórias que o próprio Lúcio vai introduzindo para ilustrar e tornar mais compreensíveis ao leitor as diversas situações em que se vai encontrando ao longo da sua existência asinina. A nossa intenção, contudo, não é a de sermos exaustivos. Constatamos, portanto, que não só não há um único narrador, como também há diversas narrativas, contadas com intuitos distintos e adequadas às mais diversas situações. Os exemplos referidos comprovam isto mesmo: a história de Sócrates se, de certo modo, contribui para suavizar uma parte difícil da jornada - tal como a leitura do romance - tem, também, a função de situar o leitor numa região específica, habitada por bruxas e feiticeiras, familiarizando-nos com a curiosidade de Lúcio; a história de Télifron, por seu turno, é o modo que o autor encontra para explicar a estranha aparência desta personagem; já o conto de Amor e Psique surge em circunstâncias bem distintas, quando a velha se esforça por animar a jovem raptada pelos ladrões. Só no final do romance, a partir do momento em que Lúcio, por acção de Ísis, se liberta definitivamente da sua figura asinina, deixamos de encontrar narrativas deste tipo. No entanto, mesmo antes de recuperar a sua forma, Lúcio, ainda burro, descreve pormenorizadamente a celebração em honra de Ísis com todo o seu cortejo. Já anteriormente, ao apresentar o episódio que precede a sua fuga e o momento em que se deveria unir publicamente a uma criminosa, ele nos descreve todo o espectáculo representando o julgamento de Páris.

Esta não é a única riqueza do romance. $O$ autor não hesita em estabelecer uma série de comparações com figuras mitológicas, como Medeia, Fedra ou Pasífaa, cujas histórias seriam bem conhecidas dos seus leitores. Do mesmo modo, as suas descrições são verdadeiras pinturas da realidade. É fácil a quem lê visualizar e sentir o que é narrado, pelas formas, pelas cores, pelo movimento.

\section{O conto de Amor e Psique no romance de Apuleio}

O romance de Apuleio teve, ao longo dos tempos, interpretações diversas, sendo frequentemente considerado um romance iniciático. As desventuras de

${ }^{1}$ Cf. Apuleio, O Burro de Ouro, 1. 5. 1-19. 12; 2.21. 3-30. 9; e 4. 28.1-6. 24. 4, respectivamente. 
Lúcio, o burro, e tudo aquilo que sofre, o modo como recupera a forma humana, por intervenção de Ísis, são justificativos suficientes para esta interpretação. Mas a ela não é alheio o conto de Amor e Psique, que não se encontra na versão grega do romance.

De certo modo as duas histórias são paralelas. Em ambas encontramos a narração das peripécias por que os heróis - Lúcio e Psique - passam a fim de atingirem um nível superior: ele, no culto de Ísis e Osíris, como já foi dito; ela na imortalidade e no casamento com Cupido. Mas não é esta a única semelhança, já que a curiosidade é outro factor comum a ambos os heróis. A curiosidade de Lúcio está patente desde o início do romance e conservase quase até ao final: praticamente só desaparece no Livro 11, depois de ter recuperado a forma humana. É a curiosidade de Lúcio pelas artes da feitiçaria que o levam a permanecer em casa de Milão, mesmo depois do convite de Birrena. É, aliás, essa mesma curiosidade que o leva a uma relação amorosa com Fótis, a criada da casa dos seus anfitriões, que partilhava os segredos da sua senhora. E ele sofrerá as consequências de tanta curiosidade ao ver-se, contra todas as suas expectativas, transformado num burro. Mas nem assim aprende a lição e o resto da narrativa mostra-nos um burro assaz curioso, a ponto de causar a perda de um dos seus donos, um pobre hortelão de parcos recursos. Daí que seja tão significativa a alteração sofrida no final do romance, sinal de que o nosso herói atingiu um estádio superior.

Também Psique sof re as consequências da sua curiosidade. Primeiro, quando se considerava plenamente feliz com a sua sorte, deixa-se levar pela desconfiança incutida pelas suas irmãs e assim desvenda o "mistério" do marido. Mas é "cheia de curiosidade" que admira as suas armas ${ }^{2}$, o que tem como consequência ferir um dos dedos nas flechas, apaixonando-se pelo Amor. Do mesmo modo, é por curiosidade que, mais tarde ${ }^{3}$, abrirá a caixinha que Prosérpina lhe entregara, sendo possuída pelo sono infernal do Estige. Qualquer leitor minimamente atento percebe que os motivos de Psique ultrapassam a mera curiosidade. No primeiro caso, a sua ingenuidade e amor fraternal não lhe permitem ver a inveja e mesquinhez das irmãs. Ou seja, mais do que a curiosidade, são a confiança nas irmãs, a recordação do oráculo e o facto de nunca ter visto o seu marido que a levam a quebrar a promessa feita. No entanto, as consequências provamlhe como errou ao confiar nas irmãs, fazendo-a aperceber-se da sua inveja, com a consequente vingança. No segundo, contudo, o verdadeiro motivo que a leva a abrir a caixa, apesar de ter sido advertida contra isso, é o desejo de ficar mais bela para o seu amado, uma preocupação bem feminina. Não obstante, os seus actos são considerados como fruto da curiosidade, como o próprio Cupido deixa claro ao salvá-la ${ }^{4}$. As semelhanças existentes entre o conto e o romance são uma forma de mostrar ao leitor que as aventuras do burro irão ter um final feliz. Neste sentido, a história da velha tem uma dupla função: por um lado,

${ }^{2}$ Cf. Apuleio, O Burro de Ouro, 5.23.1.

${ }^{3}$ Cf. Apuleio, O Burro de Ouro, 6.21.1.

${ }^{4}$ Cf. Apuleio, O Burro de Ouro, 6. 21. 4: "Minha pobre coitada, estás a ver como ias sendo vítima, novamente, da mesma curiosidade!” [A tradução é de Delfim Leão 2007]. 
animar a jovem; por outro, mostrar a Lúcio (que a ouve à distância) que, à semelhança de Psique, também ele verá a mudança da sorte.

\section{O conto de Amor e Psique e o conto infantil}

A história de Cupido e Psique apresenta, contudo, características específicas que nos permitem encará-la como uma unidade independente e que poderia ser encontrada fora do romance de Apuleio. Estas características aproximamna do conto infantil e da sua estrutura. Para além da intenção com que a história é contada, importa realçar o modo como o é. O início é significativo: Erat in quadam urbe rex et regina. ${ }^{5}$, corresponde ao nosso tradicional "Era uma vez...”. O mesmo se pode dizer de todo o conto: um rei e uma rainha, numa certa cidade, têm três filhas, das quais a mais nova se salienta pela beleza. O que poderia ser sinal de ventura, transforma-se rapidamente em problema, pois não só afasta eventuais pretendentes - que a encaram como se de uma divindade se tratasse - como ainda provoca a ira de Vénus, que pede ao seu filho, Cupido, que inspire a Psique um amor pelo mais vil dos mortais. E assim, o oráculo determina que a jovem seja abandonada no cimo de um monte para contrair casamento com um monstro cruel, feroz e viperino, temido pelo próprio Júpiter:
Nec speres generum mortali stirpe creatum,
sed seuum atque ferum uipereum malum,
quod pinnis uolitans super athera cuncta fatigat
flammaque et ferro singula debilitat,
quod tremit ipse Iouis quo numina terrificantur,
fluminaque horrescunt et Stygice tenebra. ${ }^{6}$

Tal oráculo não prenuncia nada de favorável à jovem; no entanto, é ela que decide que o seu destino será cumprido. E é ao cumpri-lo que conhecerá a sua nova morada e o seu marido. A primeira, magnífica, sumptuosa, sem dúvida construída por mãos sobre-humanas. Dele sabe apenas que é gentil, carinhoso, dado que a condição para manter a felicidade consiste em nunca tentar desvendar a identidade do marido. Tudo corre às mil maravilhas. Psique até se esquece do oráculo funesto. As visitas das irmãs, contudo, e a subsequente inveja, levam-na a quebrar o pacto estabelecido com o marido. Então, para grande surpresa de Psique, ela verifica que o marido é o próprio deus do amor, em cujas armas se fere, apaixonando-se por ele. Mas a Fortuna está atenta: um leve tremor de mão e um pingo de azeite da lamparina cai no ombro do deus adormecido. Ao aperceber-se do que se passava, Cupido, irado, foge para junto da mãe, abandonando a jovem mulher grávida. Esta decide ir em busca dele, decidida a reconquistar a sua felcidade. Pelo caminho, vingase das irmãs e tenta obter o auxílio dos deuses, designadamente de Ceres e

\footnotetext{
${ }^{5}$ Apuleio, O Burro de Ouro, 4.28.1.

${ }^{6}$ Apuleio, O Burro de Ouro, 4. 33.1-2.
} 
de Juno, por cujos templos passa. Mas estas fazem-na compreender que só Vénus a poderá ajudar; a deusa está irritadíssima por ter sido enganada pelo filho e pretende punir Psique. Arrastada para casa da deusa, a jovem tem de enfrentar diversas provas, praticamente impossíveis, impostas por Vénus. No entanto, pode contar com o auxílio de entidades distintas, desde as simples formigas à águia de Júpiter, passando por uma torre e um canavial. $\mathrm{Na}$ sua última prova, Psique, mais uma vez, é culpada de incumprimento: em vez de levar a Vénus, sem a abrir, a caixinha que Prosérpina lhe dera, contendo um pó embelezador, ela decide abri-la, para poder ficar mais bela para o seu amado. Mas o que sai da caixa é um sono infernal, que imediatamente se apodera da jovem. Felizmente, Cupido apercebera-se entretanto da sua presença em casa da mãe e decidiu ir em seu socorro. É ele que recolhe o sono de novo na caixa, acorda Psique e aconselha-a a entregá-la a Vénus, enquanto ele vai pedir a intercessão de Júpiter. Aqui chega ao fim a história deste par amoroso: Júpiter concede a Psique a imortalidade e celebra o seu casamento, numa grande festa em que todos os deuses participam. Algum tempo depois nascerá a sua filha, a Alegria.

Neste resumo encontramos os vários traços do conto infantil (nalguns casos, até mesmo de lendas medievais): a jovem bela, filha de reis, o pacto com um marido desconhecido - um monstro que acaba por se tornar no deus do amor -, a inveja das irmãs, a quebra do pacto e o consequente sofrimento, a punição de Vénus com a imposição de uma série de tarefas e, por fim, o casamento que deixa entrever uma futura felicidade perene. Tudo isto encontramos em contos infantis, como a Cinderela, a Bela e o Monstro, o Príncipe Urso, para referir apenas alguns. E, tal como no conto infantil, estes tópicos contribuem para uma análise profunda do conto e das suas implicações. Há, todavia, uma outra relação entre esta história e o conto infantil - o espaço.

\section{O espaço no conto e no romance}

A questão do espaço apresenta algumas diferenças entre o conto e o romance. Neste sabe-se que a aç̧ão decorre na Grécia, iniciando-se na Tessália; sabemos também de onde é natural o narrador, onde recupera Lúcio a forma humana e qual será o seu destino final - Roma. No entanto, nem tudo no percurso de Lúcio é identificado, o que poderá dever-se ao facto de a sua narrativa conter algo de maravilhoso, de fantástico, de irreal. Se a metamorfose de Lúcio em burro tem algo de excepcional, muitas das histórias que nos conta inserem-se no âmbito do mitológico ou, pelo menos, aproximam-se dele. Aliás, o narrador não procura sequer ocultá-lo, como se depreende das constantes alusões a várias figuras mitológicas.

A leitura do conto de Amor e Psique mostra-nos que a acção decorre em vários locais distintos. No entanto, estes nunca são especificados. Não há qualquer possibilidade de uma localização efectiva dos mesmos. O rei e a rainha vivem numa cidade sem qualquer tipo de descrição. Pode ser qualquer cidade. 
Do mesmo modo, apenas sabemos que Vénus, depois de incumbir o filho da sua tarefa, se dirige ao Oceano; só sobe à sua morada, mais tarde, quando é avisada de que está lá Cupido, ferido. Dessa morada, a única coisa que nos é dita é que é a morada dos deuses. Também não há qualquer descrição, ou localização. Já o mesmo se não pode dizer do local para onde Psique é levada por Zéfiro, depois de ser deixada no cimo de um monte pelos seus familiares, como o oráculo prescrevera. Esse espaço é descrito com mais pormenores?:

"Nestes prados de tenra erva, Psique, recostada sobre um leito de suave relva aspergida pelo orvalho, acabou por repousar docemente, uma vez acalmada a enorme perturbação de espírito. E já vivificada por um sono reparador, levanta-se com o ânimo tranquilo. Avista um bosque repleto de numerosas árvores de alto porte, avista ainda uma fonte de águas cristalinas e transparentes. Mesmo ao meio do bosque, perto do lugar de onde brotava a fonte, havia um palácio real, edificado não por mãos humanas, mas antes por artes divinas. Era bem evidente, logo desde a entrada, que se estava perante a morada esplendorosa e agradável de algum deus. $\mathrm{Na}$ verdade, o tecto elevado e cuidadosamente trabalhado em madeira de tuia e em marfim, era sustentado por colunas de ouro; as paredes estavam completamente recobertas de prata cinzelada e brindavam o olhar dos visitantes com imagens de feras e de outros animais selvagens do mesmo tipo. Fora pela certa um homem admirável, ou mesmo um semideus ou até seguramente um deus, o obreiro que, com a subtileza de uma arte magnífica, havia dado a forma de feras a tanta prata. Aliás, até os pavimentos, feitos em mosaicos de minúsculas pedras preciosas talhadas à medida, desenhavam nitidamente pinturas de cores variadas. É sem dúvida muitas e muitas vezes feliz quem tem o privilégio de pisar assim gemas e jóia preciosas! Também os restantes aposentos da mansão, tanto no comprimento como na largura, eram de uma preciosidade incalculável e todos os muros, feitos de blocos de ouro maciços, resplandeciam com um fulgor natural, a ponto de a casa poder ter luz própria, se o sol a não quisesse dar, tal era o brilho dos quartos, das galerias e dos próprios banhos. As restantes riquezas reflectiam, de igual forma, o esplendor da mansão, de maneira que até se julgaria, com acerto, que o grande Júpiter havia mandado edificar este palácio celestial, para conviver com os humanos.

Atraída pelo aspecto agradável destes lugares, Psique decide aproximar-se e, ao sentir um pouco mais de confiança, atravessa o limiar da porta. Em breve, o deleite suscitado pela visão desta beleza excepcional dá-lhe alento para observar cada pormenor; na parte oposta da mansão, avista uns aposentos que exibiam uma arquitectura sublime e estavam repletos de riquezas. Nada existe que também ali se não encontrasse!”

Há uma descrição da nova morada de Psique e de toda a sua sumptuosidade, tal como da paisagem envolvente. Há uma significativa distância a separar este ambiente do mundo dos homens, como fica patente pelo facto de o acesso à nova morada de Psique só ser possibilitado pelo sopro de Zéfiro e pelo facto de a sorte de Psique ser completamente desconhecida de todos, designadamente dos pais. Além disso, temos uma paisagem idílica envolvendo

\footnotetext{
${ }^{7}$ Apuleio, O Burro de Ouro, 5.1.1-2. 1 [A tradução é de Delfim Leão 2007].
} 
um palácio sobrenatural, cuja riqueza se encontra aberta, exposta, como se os seus proprietários confiassem nos outros, ou estes se encontrassem totalmente ausentes. Esta exposição, esta ausência de preocupação com a segurança surpreendem Psique tanto ou mais do que a sumptuosidade que tem perante os olhos.

Estes aspectos denotam uma transposição para um outro mundo, diferente do humano, que tanto pode indicar um nível intermédio na vida de Psique, a sua evolução de jovem humana até à imortal mulher de Cupido, como a aproximação ao maravilhoso, ao fantástico dos contos. E este fantástico significa a inexistência de um espaço específico, o não-espaço, o maravilhoso, o universal, tal como se apresenta nos contos de fadas.

\section{Nota bibliográfica}

Apuleio (1967), Psyches et Cupidinis (Fabula) (ed. Pierre Grimal). Avignon, Maison Aubanel.

Apuleio (2007), O Burro de Ouro (tradução do Latim e introdução de Delfim Leão). Lisboa, Cotovia. 